\title{
Effects of hemodialysis, peritoneal dialysis, and renal transplantation on the quality of life of patients with end-stage renal disease
}

\author{
(Dijuan Zhang' \\ (iD) Yannan Guo \\ (iD) Huing ${ }^{2}$
}

1. Department of Nephrology, West China Second University Hospital of Sichuan University \& Key Laboratory of Birth Defects and Related Disease of Women and Children (Sichuan University), Ministry of Education, Chengdu 610041, Sichuan Province, China. 2. Department of Medicine, Chengdu Hospital of Sichuan Armed Police Corps, Chengdu 610041, Sichuan Province, China.

http://dx.doi.org/10.1590/1806-9282.66.9.1229

\section{SUMMARY}

OBJECTIVE: To evaluate the effects of hemodialysis, peritoneal dialysis, and renal transplantation on the quality of life of patients with end-stage renal disease (ESRD) and analyze the influencing factors.

METHODS: A total of 162 ESRD patients who received maintenance hemodialysis, continuous ambulatory peritoneal dialysis, and renal transplantation from February 2017 to March 2018 in our hospital were divided into a hemodialysis group, a peritoneal dialysis group, and a renal transplantation group. The baseline clinical data, serum indices, as well as environmental factors such as education level, marital status, work, residential pattern, household income, and expenditure were recorded. The quality of life was assessed using the short-form 36-item (SF-36) scale reflecting the Physical Component Summary (PCS) and the Mental Component Summary (MCS). One-way analysis of variance and logistic stepwise multiple regression analysis were performed to analyze the factors influencing the quality of life.

RESULTS: The renal transplantation group had the highest average scores for all dimensions of the SF-36 scale. The PCS and MCS scores of this group were higher than those of the hemodialysis and peritoneal dialysis groups. The peritoneal dialysis group had higher scores for physical functioning, physical role, bodily pain, general health, mental health, PCS, and MCS than those of the hemodialysis group. Age, HGB, GLU, and ALP were the main factors influencing PCS. Age, education level, residential pattern, medication expenditure, and monthly per capita income mainly affected MCS.

CONCLUSION: In terms of quality of life, renal transplantation is superior to peritoneal dialysis and hemodialysis.

KEYWORDS: Renal dialysis. Peritoneal dialysis. Kidney transplantation. Kidney failure, chronic.

\section{INTRODUCTION}

End-stage renal disease (ESRD) is the end-stage of chronic kidney disease and is mainly manifested as an evident decrease in renal function. Metabolic waste cannot be independently eliminated, causing electrolyte imbalance and a series of poisoning symptoms ${ }^{1}$. As the population ages, the incidence rate of ESRD increases annually. Even with the continuous development of medical standards, the mortality rate remains high ${ }^{2}$. Renal replacement therapy is commonly used for ESRD in clinical practice, including 
hemodialysis, peritoneal dialysis, and renal transplantation ${ }^{3}$. Although life expectancy can be consequently increased, either treatment must be maintained for a long time, which has a serious impact on patients both physiologically and psychologically 4 .

The quality of life is closely related to society and family, which has been defined by WHO as an individual's perception of their position in life in the context of the culture and value systems in which they live and in relation to their goals, expectations, standards, and concerns ${ }^{5}$. For ESRD patients, chronic dialysis evidently affects the quality of life, manifested as a decrease of social interaction and physical functioning, an increase of depression risk, and aggravation of symptoms including leg restlessness, muscle weakness, and fatigue ${ }^{6}$. The quality of life of patients with ESRD is poorer than that of the general population, which has been highly related to malnutrition ${ }^{7-9}$. Besides, the quality of life differs depending on the modality of renal replacement therapy. For instance, patients receiving renal transplantation have a better quality of life than those undergoing dialysis ${ }^{10}$. It is a concept including physical, psychological, social function, and economic dimensions as an important index for evaluating the prognosis of ESRD patients ${ }^{11}$. Additionally, the mortality and length of hospitalization of dialysis patients can be independently predicted by the quality of life, which has thus been suggested as a valuable supplement to clinical outcome measures ${ }^{12}$.

Until now, how the quality of life of ESRD patients is affected by non-medical factors assessed by preference-based measures remains elusive. Therefore, it is necessary to determine the best treatment method and related factors, aiming to prolong life expectancy and improve the quality of life. We herein evaluated the effects of three alternative therapies on the quality of life of ESRD patients and the related influencing factors, providing a theoretical basis for the selection of treatment methods.

\section{METHODS}

\section{Baseline clinical data}

A total of 162 ESRD patients who received maintenance hemodialysis, continuous ambulatory peritoneal dialysis, and renal transplantation from February 2017 to March 2018 in our hospital were enrolled. Among them, 52 patients received hemodialysis, consisting of 32 males and 20 females aged 28-84 years old, (58.92 \pm 10.32 on average). There were 16 cases of primary critical chronic glomerulonephritis, 10 cases of hypertensive renal injury, 8 cases of diabetic nephropathy, 6 cases of polycystic kidney disease, 5 cases of gouty nephropathy, and 7 cases with unknown causes. Hemodialysis was carried out 3 times weekly, $4 \mathrm{~h}$ each time. Sixty patients received peritoneal dialysis, comprising 36 males and 24 females aged 26-81 years old, (59.63 \pm 10.78 on average). There were 19 cases of primary critical chronic glomerulonephritis, 11 cases of hypertensive renal injury, 10 cases of diabetic nephropathy, 7 cases of polycystic kidney disease, 5 cases of gouty nephropathy, and 8 cases with unknown causes. The peritoneal dialysis solution was refreshed 4 times daily, 2L each time. Fifty patients were subjected to renal transplantation, including 30 males and 20 females aged 27-83 years old, (59.63 \pm 9.96 on average). There were 13 cases of primary critical chronic glomerulonephritis, 8 cases of hypertensive renal injury, 10 cases of diabetic nephropathy, 6 cases of polycystic kidney disease, 4 cases of gouty nephropathy, and 9 cases with unknown causes. This study was approved by the ethics committee of our hospital, and written consent was obtained from all patients.

Inclusion criteria: 1) meeting the diagnostic criteria of ESRD; 2) age $>18$ years; 3 ) receiving hemodialysis and peritoneal dialysis for over 3 months, or renal transplantation over 6 months.

Exclusion criteria: 1) primary critical autoimmune diseases; 2) complication with malignant tumors; 3) complication with acute infection; 4) complication with severe liver and pulmonary diseases; 5) mental diseases or inability to cooperate with examinations; 6) patients who died within 3 months of enrollment.

\section{Laboratory testing}

Age, body mass index (BMI), gender, treatment time, blood pressure, levels of hemoglobin (HGB), low-density lipoprotein-cholesterol (LDL-C), calcium-phosphorus (Ca, P), total cholesterol (TCH), serum creatinine (SCR), urea nitrogen (UA), blood glucose (GLU), alkaline phosphatase (ALP), and C-reactive protein (CRP), as well as environmental factors such as educational level, marital status, work, residential pattern, household income, and expenditure were recorded.

\section{Investigation tool}

The quality of life was assessed using the shortform 36-item (SF-36) scale ${ }^{13}$, which was completed 
under the guidance of researchers. The SF-36 scale consists of 8 dimensions, i.e. physical functioning $(\mathrm{PF})$, role physical (RP), bodily pain (BP), general health (GH), vitality (VT), social functioning (SF), role emotional (RE), and mental health (MH). The score of each dimension ranges from 0 to 100 points, and the higher the score, the better the quality of life. The Physical Component Summary (PCS) is reflected by PF, RP, BP and GH, and the Mental Component Summary (MCS) is reflected by VT, SF, RE, and MH.

\section{Statistical analysis}

All data were statistically analyzed by SPSS16.0 software. Categorical data such as the scale scores were expressed as mean \pm standard deviation. The comparisons between the two groups were performed by the independent $\mathrm{t}$-test, and those among multiple groups were conducted with one-way analysis of variance and logistic stepwise multiple regression analysis. $\mathrm{P}<0.05$ was considered statistically significant.

\section{RESULTS}

Baseline clinical data

The three groups had similar age, gender ratio, BMI, blood pressure, and blood biochemical indices $(\mathrm{P}>0.05)$ (Table 1).

\section{SF-36 scale scores}

The renal transplantation group had the highest average scores at all dimensions of the SF-36 scale. The PCS and MCS scores of this group were higher than those of the hemodialysis and peritoneal dialysis groups. The peritoneal dialysis group had higher scores of PF, RP, BP, GH, MH, PCS, and MCS than those of the hemodialysis group $(\mathrm{P}<0.05)$ (Supplementary File, Table S1).

Univariate analysis of the effects of environmental factors on the quality of life

Univariate analysis showed that the PCS and MCS of ESRD patients were affected by whether they lived alone. MCS was associated with educational level, monthly drug expenditure, and monthly income per capita, whereas PCS was not related with other factors (Table 2).

Multivariate analysis of factors affecting the quality of life

Variable assignments are listed in Table S2 (Supplementary File). Multivariate analysis showed that age, HGB, GLU, and ALP were the main factors influencing PCS. Age, education level, residential pattern, medication expenditure, and monthly per capita income mainly affected MCS (Figure 1).

TABLE 1. BASELINE CLINICAL DATA

\begin{tabular}{|c|c|c|c|c|}
\hline Index & Hemodialysis group $(n=52)$ & Peritoneal dialysis group $(n=60)$ & Renal transplantation group $(n=50)$ & $P$ \\
\hline Age (year) & $58.92 \pm 10.32$ & $59.63 \pm 10.78$ & $59.63 \pm 9.96$ & 0.723 \\
\hline Male [case (\%)] & $32(61.54 \%)$ & $36(60.00 \%)$ & $30(60.00 \%)$ & 0.983 \\
\hline Treatment time (month) & $22.12 \pm 3.65$ & $21.65 \pm 2.86$ & $23.21 \pm 3.21$ & 0.256 \\
\hline $\mathrm{BMI}\left(\mathrm{kg} \cdot \mathrm{m}^{-2}\right)$ & $24.53 \pm 3.82$ & $26.11 \pm 2.78$ & $25.33 \pm 3.26$ & 0.384 \\
\hline Systolic pressure $(\mathrm{mmHg})$ & $123.37 \pm 12.89$ & $128.18 \pm 13.33$ & $127.87 \pm 13.46$ & 0.543 \\
\hline Diastolic pressure $(\mathrm{mmHg})$ & $73.25 \pm 7.63$ & $76.34 \pm 8.17$ & $81.46 \pm 9.28$ & 0.125 \\
\hline $\mathrm{HGB}\left(\mathrm{g} \cdot \mathrm{L}^{-1}\right)$ & $73.23 \pm 4.28$ & $78.64 \pm 6.48$ & $76.84 \pm 7.24$ & 0.638 \\
\hline $\mathrm{LDL}-\mathrm{C}\left(\mathrm{mmol} \cdot \mathrm{L}^{-1}\right)$ & $2.49 \pm 0.87$ & $2.53 \pm 0.91$ & $2.52 \pm 1.03$ & 0.223 \\
\hline $\mathrm{Ca}\left(\mathrm{mmol} \cdot \mathrm{L}^{-1}\right)$ & $2.09 \pm 0.26$ & $2.12 \pm 0.31$ & $2.21 \pm 0.35$ & 0.316 \\
\hline $\mathrm{P}\left(\mathrm{mmol} \cdot \mathrm{L}^{-1}\right)$ & $1.65 \pm 0.43$ & $1.68 \pm 0.52$ & $1.71 \pm 0.64$ & 0.563 \\
\hline $\mathrm{TCH}\left(\mathrm{mmol} \cdot \mathrm{L}^{-1}\right)$ & $4.83 \pm 1.6$ & $4.76 \pm 1.16$ & $4.98 \pm 1.23$ & 0.303 \\
\hline $\operatorname{SCR}\left(\mathrm{mmol} \cdot \mathrm{L}^{-1}\right)$ & $81.34 \pm 18.95$ & $76.56 \pm 16.35$ & $83.86 \pm 17.35$ & 0.379 \\
\hline UA $\left(\mathrm{mol} \cdot \mathrm{L}^{-1}\right)$ & $22.26 \pm 3.32$ & $23.44 \pm 3.56$ & $22.35 \pm 3.67$ & 0.089 \\
\hline $\mathrm{GLU}\left(\mathrm{mmol} \cdot \mathrm{L}^{-1}\right)$ & $6.85 \pm 1.23$ & $7.02 \pm 1.85$ & $6.44 \pm 1.26$ & 0.095 \\
\hline $\operatorname{ALP}\left(g \cdot L^{-1}\right)$ & $30.13 \pm 4.28$ & $30.42 \pm 3.98$ & $31.44 \pm 3.13$ & 0.125 \\
\hline $\operatorname{CRP}\left(m g \cdot L^{-1}\right)$ & $4.89 \pm 1.06$ & $4.96 \pm 1.32$ & $4.85 \pm 0.93$ & 0.113 \\
\hline
\end{tabular}

ALP: alkaline phosphatase; BMI: body mass index; Ca: calcium; CRP: C-reactive protein; GLU: glucose; HGB: hemoglobin; LDL-C: low-density lipoprotein-cholesterol; P: phosphorus; SCR: serum creatinine; TCH: total cholesterol; UA: urea nitrogen. 
TABLE 2. UNIVARIATE ANALYSIS OF THE EFFECTS OF ENVIRONMENTAL FACTORS ON THE QUALITY OF LIFE

\begin{tabular}{|c|c|c|c|c|c|c|}
\hline Factor & PCS & $\mathrm{F} / \mathrm{t}$ & $\mathrm{P}$ & MCS & $\mathrm{F} / \mathrm{t}$ & $\mathrm{P}$ \\
\hline Educational level & & \multirow[t]{5}{*}{0.728} & \multirow[t]{5}{*}{0.288} & & \multirow[t]{5}{*}{3.249} & \multirow[t]{5}{*}{0.036} \\
\hline Secondary technical school and above $(n=30)$ & $52.70 \pm 16.54$ & & & $62.58 \pm 16.13$ & & \\
\hline Junior high school $(n=54)$ & $55.71 \pm 15.24$ & & & $55.92 \pm 12.24$ & & \\
\hline Primary school $(n=58)$ & $53.35 \pm 13.69$ & & & $48.02 \pm 8.18$ & & \\
\hline Illiteracy $(n=20)$ & $54.51 \pm 14.84$ & & & $42.54 \pm 6.19$ & & \\
\hline Marital status & & \multirow[t]{3}{*}{0.68} & \multirow[t]{3}{*}{0.497} & & \multirow[t]{3}{*}{0.511} & \multirow[t]{3}{*}{0.61} \\
\hline Married $(n=124)$ & $54.95 \pm 14.62$ & & & $56.29 \pm 12.31$ & & \\
\hline Single or widowed $(n=38)$ & $56.76 \pm 13.42$ & & & $55.15 \pm 11.03$ & & \\
\hline Living alone & & \multirow[t]{3}{*}{3.332} & \multirow[t]{3}{*}{0.001} & & \multirow[t]{3}{*}{4.871} & \multirow[t]{3}{*}{0.000} \\
\hline Yes $(n=36)$ & $46.54 \pm 13.25$ & & & $45.96 \pm 12.28$ & & \\
\hline No $(n=126)$ & $55.36 \pm 14.21$ & & & $59.35 \pm 15.12$ & & \\
\hline Work & & \multirow[t]{3}{*}{0.635} & \multirow[t]{3}{*}{0.526} & & \multirow[t]{3}{*}{0.718} & \multirow[t]{3}{*}{0.474} \\
\hline Yes $(n=28)$ & $55.02 \pm 14.93$ & & & $57.54 \pm 12.02$ & & \\
\hline No $(n=134)$ & $53.26 \pm 12.98$ & & & $59.37 \pm 12.31$ & & \\
\hline Monthly drug expenditure $(X)$ & & \multirow[t]{4}{*}{0.431} & \multirow[t]{4}{*}{0.673} & & \multirow[t]{4}{*}{4.459} & \multirow[t]{4}{*}{0.005} \\
\hline$X \leq 1500$ CNY $(n=56)$ & $56.84 \pm 14.32$ & & & $48.68 \pm 10.22$ & & \\
\hline $1500<X<2500$ CNY $(n=62)$ & $55.81 \pm 13.13$ & & & $58.90 \pm 12.21$ & & \\
\hline$X \geq 2500$ CNY $(n=44)$ & $56.32 \pm 15.54$ & & & $65.07 \pm 17.17$ & & \\
\hline Monthly income per capita (X) & & \multirow[t]{5}{*}{1.189} & \multirow[t]{5}{*}{0.332} & & \multirow[t]{5}{*}{5.749} & \multirow[t]{5}{*}{$<0.001$} \\
\hline$X \leq 300$ CNY $(n=18)$ & $58.02 \pm 16.02$ & & & $42.32 \pm 9.18$ & & \\
\hline $301<X<800$ CNY $(n=25)$ & $53.14 \pm 13.89$ & & & $54.12 \pm 13.76$ & & \\
\hline $800<X<1500$ CNY $(n=32)$ & $56.14 \pm 14.42$ & & & $59.09 \pm 15.01$ & & \\
\hline$X \geq 1500$ CNY $(n=60)$ & $54.82 \pm 15.43$ & & & $63.32 \pm 17.37$ & & \\
\hline
\end{tabular}

CNY: Chinese Yuan; MCS: Mental Component Summary; PCS: Physical Component Summary.

FIGURE 1. MULTIVARIATE ANALYSIS OF FACTORS AFFECTING THE QUALITY OF LIFE. ALP: ALKALINE PHOSPHATASE; GLU: GLUCOSE; HGB: HEMOGLOBIN; MCS: MENTAL COMPONENT SUMMARY; OR: ODDS RATIO; PCS: PHYSICAL COMPONENT SUMMARY.

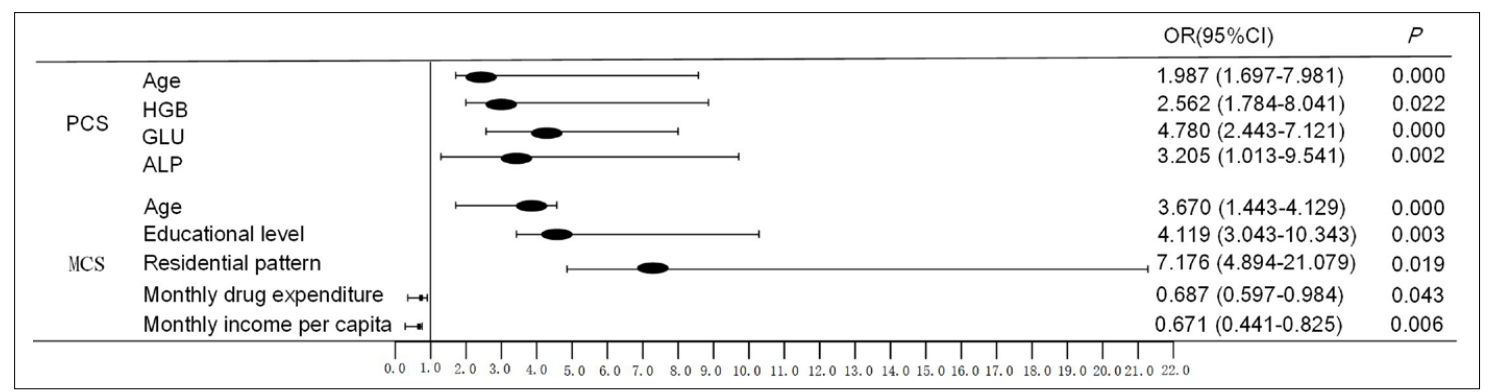

\section{DISCUSSION}

The purpose of ESRD treatment is no longer only to alleviate pain, prolong life, reduce complications and hospitalization rates. Improving patients' quality of life and returning them to family and society, or even getting them as close to normal life as possible has become an important direction of treatment ${ }^{14}$. There is still controversy about the choice of alternative treatments and the evaluation of therapeutic effects. The SF-36 scale is an important measurement of the quality of life and has been widely used in ESRD. At present, there is less analysis of the quality of life and its influencing factors in patients with ESRD in China compared with hemodialysis, peritoneal dialysis, and kidney transplantation.

In this study, the quality of life of renal transplant patients is better than that of patients who receive hemodialysis and peritoneal dialysis, probably because kidney transplant patients can autonomously excrete metabolic waste without the need for auxiliary equipment, regulate endocrine levels, and improve nutritional status. PF, BP, GH, and MH of hemodialysis 
patients were worse than those of patients receiving peritoneal dialysis, and the differences between them were statistically significant. Makkar et al. ${ }^{15}$ found that the quality of life of patients undergoing hemodialysis was significantly poorer than that of peritoneal dialysis patients. Possibly, compared with hemodialysis, peritoneal dialysis is simpler and easier to master, and patients do not need to rely on others to complete it themselves, which preserves their dignity. Hemodialysis may bring physical pain to the patients during arteriovenous fistula puncture, and is likely to cause hypotension, arrhythmia, or worsen heart function damage $\mathrm{e}^{16}$. In contrast, peritoneal dialysis is relatively stable, with no sudden changes in body fluid volume, and a better protective effect on residual kidney function. In addition, the dependence of patients on hemodialysis machines severely limits their life and may also have a negative impact on their mentality ${ }^{17}$.

This study analyzed the factors affecting the quality of life, and the results showed that age, education level, residential pattern, medication expenses, and monthly income were the main factors affecting MCS. For each therapy, ESRD patients need longterm maintenance treatment and medical review. Due to expensive medical expenses, and stress from the psychological, family, and social aspects, the patients often experience negative emotions such as anxiety and depression. The lack of roles in family and society, the decline in self-care ability, and even the need for family care have also seriously reduced the quality of life of patients ${ }^{18}$. Neumann et al. ${ }^{19}$ found that the MCS scores of elderly patients were better than those of younger ones, indicating that the patients' understanding of the disease and the regulation of their own emotions were associated with age. Lu et al. ${ }^{14}$ reported that elderly patients were more likely to accept their own limitations, so they were satisfied more easily. A higher level of education may lead to better mastery of dialysis operations and principles and better compliance with medical procedures, all contributing to the improvement of quality of life.

In this study, the main factors affecting patients' PCS included age, HGB, GLU, and ALP. Elderly patients have worse physical health due to degenerative organ function, more underlying diseases, and low immunity. Zazzeroni et al. ${ }^{20}$ also reported that age was the main influencing factor for the PCS score of quality of life. HGB is an important indicator of whether there is anemia. Anemia is a common complication of ESRD, which can lead to arrhythmia and decreased heart function, which in turn leads to a series of cardiovascular events, and have a serious impact on patients' quality of life. Diabetes is one of the important factors that cause ESRD, and GLU concentration can reflect the severity of ESRD patients ${ }^{21}$. Marcacuzco et al. ${ }^{22}$ found that the higher the GLU concentration, the more likely ESRD patients were to die. In a study of 1,753 patients with renal failure dialysis, high levels of ALP significantly affected all-cause mortality, cardiovascular mortality, and recent survival2 ${ }^{23}$. Herein, ALP was a major factor affecting the quality of life of ESRD patients.

\section{CONCLUSION}

In summary, in terms of the quality of life of patients, renal transplantation in 3 alternative treatment methods is superior to peritoneal dialysis and hemodialysis, and the quality of life of hemodialysis patients is even worse. In the future, it is necessary to expand the sample for multi-center prospective research, and improve patient data for different treatment times, so as to provide better interventions to further improve the quality of life.

\section{Acknowledgments}

This study was supported by Grants from the Science and Technology Bureau of Sichuan Province (No. 2019YFSO240).

\section{Author's Contribution}

LZ: Study design, data collection and analysis, manuscript drafting; Yannan Guo: Study design, significant manuscript revision; Hua Ming: data collection and analysis, manuscript drafting. 


\section{RESUMO}

OBJETIVO: Avaliar os efeitos da hemodiálise, diálise peritoneal e transplante renal na qualidade de vida de pacientes na última fase da doença renal terminal (ESRD), bem como analisar os fatores influentes.

MÉTODOS: Um total de 162 pacientes de ESRD receberam hemodiálise de manutenção, diálise peritoneal ambulatorial contínua e transplante renal de fevereiro de 2017 a março de 2018 em nosso hospital. Eles foram divididos em grupo de hemodiálise, grupo de diálise peritoneal e grupo de transplante renal. Foram analisados os dados clínicos de base, índices-chave e os fatores ambientais, como nivel educacional, estado civil, emprego, padrão residencial, renda e gasto familiar. A qualidade de vida foi avaliada pelo uso da escala de forma reduzida de 36 itens (SF-36), que reflete o Resumo da Escala Física (PCS) e o Resumo dos Componentes Mentais (PCS). Análise unidirecional de variações e análise de regressão logística múltipla foram realizadas para analisar os fatores que influenciam a qualidade de vida.

RESULTADOS: O grupo de transplante renal teve os maiores pontos médios em todas as dimensões da escala SF-36. Os pontos PCS e MCS desse grupo foram mais altos que os dos grupos de hemodiálise e diálise peritoneal. Além disso, o grupo de diálise peritoneal teve pontos mais altos em funcionamento físico, função física, dor corporal, saúde geral, saúde mental, PCS e MCS do que os do grupo de hemodiálise. Idade, HGB, GLU e ALP foram os principais fatores que influenciaram a PCS. Idade, nível educacional, padrão residencial, gastos em medicamentos e renda mensal per capita afetaram principalmente o MCS.

CONCLUSÃO: Quanto à qualidade de vida, o transplante renal é melhor que a diálise peritoneal e a hemodiálise.

PALAVRAS-CHAVE: Diálise renal. Diálise peritoneal. Transplante de rim. Falência renal crônica.

\section{REFERENCES}

1. Baumgaertel MW, Kraemer M, Berlit P. Neurologic complications of acute and chronic renal disease. Handb Clin Neurol. 2014;119:383-93.

2. Ku E, Glidden DV, Johansen KL, Sarnak M, Tighiouart H, Grimes B, et al. Association between strict blood pressure control during chronic kidney disease and lower mortality after onset of end-stage renal disease. Kidney Int. 2015;87(5):1055-60.

3. Robinson BM, Akizawa T, Jager KJ, Kerr PG, Saran R, Pisoni RL. Factors affecting outcomes in patients reaching end-stage kidney disease worldwide: differences in access to renal replacement therapy, modality use, and haemodialysis practices. Lancet. 2016;388(10041):294-306.

4. Vidal E, van Stralen KJ, Chesnaye NC, Bonthuis M, Holmberg C, Zurowska $A$, et al; ESPN/ERA-EDTA Registry. Infants requiring maintenance dialysis: outcomes of hemodialysis and peritoneal dialysis. Am J Kidney Dis. 2017;69(5):617-25

5. World Health Organization. WHOQOL: measuring quality of life. [cited 2020 Jan 15]. Available from: https://www.who.int/healthinfo/survey/ whoqol-qualityoflife/en/

6. Yang F, Griva K, Lau T, Vathsala A, Lee E, Ng HJ, et al. Health-related quality of life of Asian patients with end-stage renal disease (ESRD) in Singapore. Qual Life Res. 2015;24(9):2163-71.

7. Feroze U, Noori N, Kovesdy CP, Molnar MZ, Martin D|, Reina-Patton A, et al. Quality-of-life and mortality in hemodialysis patients: roles of race and nutritional status. Clin | Am Soc Nephrol. 2011;6(5):1100-11.

8. Md Yusop NB, Yoke Mun C, Shariff ZM, Beng Huat C. Factors associated with quality of life among hemodialysis patients in Malaysia. PLoS One. 2013:8(12):e84152.

9. Jaar BG, Chang A, Plantinga L. Can we improve quality of life of patients on dialysis? Clin J Am Soc Nephrol. 2013;8(1):1-4.

10. Wu AW, Fink NE, Marsh-Manzi JV, Meyer KB, Finkelstein FO, Chapman $M M$, et al. Changes in quality of life during hemodialysis and peritoneal dialysis treatment: generic and disease specific measures. I Am Soc Nephrol. 2004:15(3):743-53.

11. Wang IK, Lin CL, Sung FC. Lower risk of de novo congestive heart failure in peritoneal dialysis patients compared with hemodialysis patients. Int J Cardiol. 2017;229:123.

12. Pagels AA, Söderkvist BK, Medin C, Hylander B, Heiwe S. Health-related quality of life in different stages of chronic kidney disease and at initiation of dialysis treatment. Health Qual Life Outcomes. 2012;10:71.
13. Ho YF, Li IC. The influence of different dialysis modalities on the quality of life of patients with end-stage renal disease: a systematic literature review. Psychol Health. 2016;31(12):1435-65.

14. Lu R, Estremadoyro C, Chen X, Zhu M, Ribeiro LC, Yan Y, et al. Hemodialysis versus peritoneal dialysis: an observational study in two international centers. Int | Artif Organs. 2017. doi: 10.5301/ijao.5000656

15. Makkar V, Kumar M, Mahajan R, Khaira NS. Comparison of outcomes and quality of life between hemodialysis and peritoneal dialysis patients in Indian ESRD population. J Clin Diagn Res. 2015;9(3):OC28-31.

16. Wong B, Ravani P, Oliver MJ, Holroyd-Leduc J, Venturato L, Garg AX, et al. Comparison of patient survival between hemodialysis and peritoneal dialysis among patients eligible for both modalities. Am | Kidney Dis. 2018;71(3):344-51.

17. Polikandrioti M, Koutelekos I, Gerogianni G, Stefanidou S, Kyriakopoulos V, Floraki E, et al. Factors associated with hemodialysis machine dependency. Med Arch. 2017;71(2):122-7.

18. Bristowe K, Horsley HL, Shepherd K, Brown H, Carey I, Matthews B, et al. Thinking ahead: the need for early advance care planning for people on haemodialysis: a qualitative interview study. Palliat Med. 2015;29(5):443-50.

19. Neumann D, Mau W, Wienke A, Girndt M. Peritoneal dialysis is associated with better cognitive function than hemodialysis over a one-year course. Kidney Int. 2018;93(2):430-8.

20. Zazzeroni L, Pasquinelli G, Nanni E, Cremonini V, Rubbi I. Comparison of quality of life in patients undergoing hemodialysis and peritoneal dialysis: a systematic review and meta-analysis. Kidney Blood Press Res. 2017;42(4):717-27.

21. Yang YF, Li TC, Li Cl, Liu CS, Lin WY, Yang SY, et al. Visit-to-visit glucose variability predicts the development of end-stage renal disease in type 2 diabetes: 10-year follow-up of Taiwan diabetes study. Medicine (Baltimore). 2015;94(44):e1804

22. Marcacuzco A, Jiménez-Romero C, Manrique A, Calvo J, Cambra F, Caso Ó, et al. Outcome of patients with hemodialysis or peritoneal dialysis undergoing simultaneous pancreas-kidney transplantation. Comparative study. Clin Transplant. 2018;32(6):e13268.

23. Chin Al, Tong K, McVicar IP. Successful hemodialysis arteriovenous fistula creation in a patient with continuous-flow left ventricular assist device support. Am J Kidney Dis. 2017;69(2):314-6. 